\title{
Ancillary services market framework for voltage control in distribution networks with microgrids
}

\author{
A.G. Madureira*, J.A. Peças Lopes \\ Institute for Systems and Computer Engineering of Porto and Faculty of Engineering of the University of Porto, Portugal
}

\section{A R T I C L E I N F O}

\section{Article history:}

Received 13 June 2011

Received in revised form 1 November 2011

Accepted 28 December 2011

\section{Keywords:}

Ancillary services markets

Voltage control

Distributed Generation

Microgrids

\begin{abstract}
A B S T R A C T
In this paper, a proposal for an ancillary services (AS) market framework addressing voltage control in multi-microgrid systems is presented. This var market proposal for MV distribution systems can be adopted to involve Distributed Generation (DG) units and microgrids in AS provision. In the approach that was developed each player is given the opportunity to submit its bid to the var market and the market settlement is performed using an Optimal Power Flow (OPF) formulation in order to minimize the price of reactive power purchased by the Distribution System Operator (DSO). This market is based on var capacity use and runs daily after the scheduling of the generation units for a period of operation of one day.
\end{abstract}

(c) 2012 Elsevier B.V. All rights reserved.

\section{Introduction}

During the last decades, the restructuring of the electric power industry has caused a shift in paradigm in terms of operation philosophy and control strategies. Certain activities that were previously considered part of the integrated electricity supply (such as voltage control and frequency control) are now regarded as separate services and often independently managed and accounted for [1]. These services are called AS and are essential in order to support the transmission of electric power from generation to consumption while meeting safety, security and reliability requirements. In the future AS provision should involve also the DSO and the distribution system, namely to deal with local AS, in addition to the Transmission System Operator and the transmission infrastructure.

On the other hand, electricity supply is expected to become increasingly dependent on DG and, particularly, on RES. Presently, most DG units are limited to injecting power into the distribution system and are not involved in network operation, especially those based on intermittent sources such as Photo-Voltaic (PV) and wind generation. The main drawbacks usually pointed out for rejecting DG participation in network operation are its relatively small size, unreliability and costly operation although some recent studies tend to contradict these views [2]. However, by aggregating some of these resources, it is possible to create larger market players,

\footnotetext{
* Corresponding author at: INESC Porto, Campus da FEUP, Rua Dr. Roberto Frias, 378 4200-465 Porto, Portugal. Tel.: +351 22209 4000; fax: +351 222094150.

E-mail addresses: agm@inescporto.pt, andre.g.madureira@inescporto.pt (A.G. Madureira).
}

which can help mitigating many of their apparent disadvantages [3]. Through the Virtual Power Plant (VPP) concept, aggregated DG units and loads may be able to participate in electricity markets and provide AS. In this context, the microgrid and multi-microgrid concepts may be exploited.

In this context, competitive markets opened to DER participation for providing both energy and AS should be encouraged since they may contribute to improve overall efficiency and facilitate competition between all players in the electrical power system. In particular, AS markets are regarded as a great opportunity for both DG and microgrids, especially for voltage control and reserve provision $[3,4]$.

Under a competitive framework, a market proposal for reactive power use is presented in the following sections, based on a dayahead market following the dispatch of generation units.

\section{Multi-microgrid control and management architecture}

The new operation paradigm in electrical power systems involves a growing penetration of microgeneration in LV networks based on the development and extension of the microgrid concept [5]. Furthermore, MV distribution grids of the future will include a massive penetration of DG and microgrids (which can operate as active cells) that should be managed under a coordinated and hierarchical control approach. This new type of system will be referred to in this paper as the multi-microgrid system.

Therefore, the concept of multi-microgrids consists of a highlevel structure, formed at the MV level, consisting of LV microgrids and DG units directly connected to the MV level on several adjacent feeders [6]. For the purpose of grid control and management, 


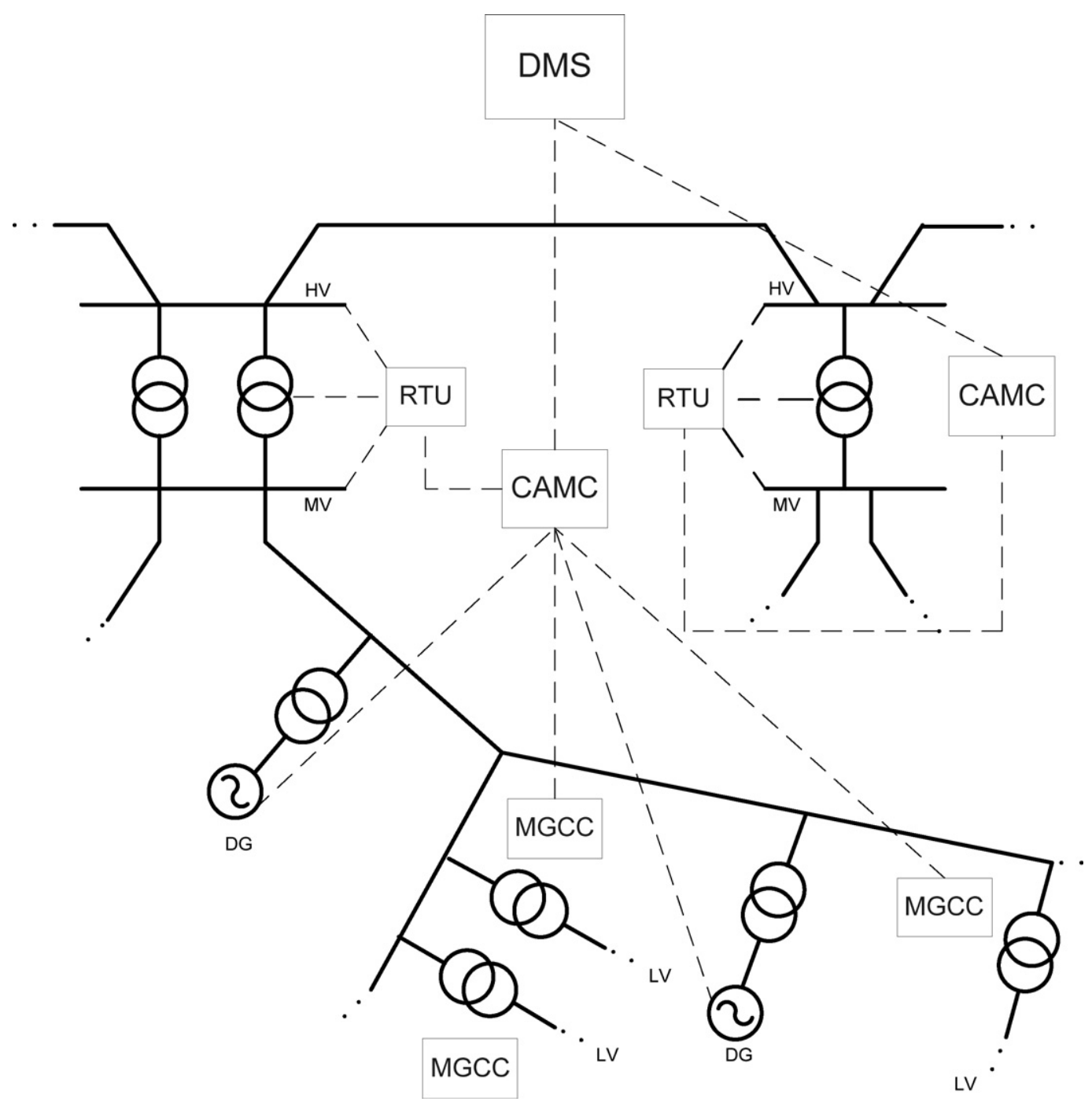

Fig. 1. Control and management architecture of a multi-microgrid system.

microgrids, DG units and MV loads under active Demand Side Management control can be considered as active cells in this new type of power system.

An effective management of this type of system requires the development of a hierarchical control architecture, where intermediary control will be exercised by a new controller - the Central Autonomous Management Controller (CAMC) - to be installed at the MV bus level of a HV/MV substation, under the responsibility of the DSO, which will be in charge of each multi-microgrid system [6]. The CAMC will behave like a small Distribution Management System (DMS) able to tackle the scheduling problem of generating units (namely DG sources) and other control devices. The architecture of this type of system is presented in Fig. 1. This approach was proposed within the framework of EU project More MicroGrids [7].

In this context, the deployment and exploitation of a communication infrastructure as a means of achieving full observability of the distribution network is crucial. This may be achieved by exploiting a smart metering infrastructure, which will allow coordinated and integrated management of individual active cells for managing the distribution network efficiently.

Consequently, from the multi-microgrid system perspective, the coordination of multiple microgrids and other DG sources and loads at the MV level can be attained by exploiting the VPP concept: by aggregating components and operating as VPPs, microgrids are able to bid and offer not only energy but also AS to the external power system through the corresponding MicroGrid Central Controller (MGCC) [6].

\section{Market proposal for voltage control}

For the model proposed in this paper, the main product of the AS market for voltage control is var utilization. In this case the DSO will run an AS market for voltage control for the distribution system that accommodates the var bids from the several players and distributes the var needs among them in order to satisfy the reactive power requirements in normal operation conditions. The proposal is based on a day-ahead AS market for voltage control. This market should run after the scheduling of the main generation units and be based on forecast data for RES production and load consumption for the next period of operation.

In this model, the DSO will act as the sole buyer of var and is responsible for the market settlement. In order to achieve the market settlement, the bids from the several var sources are sorted in order to meet the requirements for reactive power demand for each hour of the period of operation considered (which should be set by the DSO), subject to several technical and operational constraints. This procedure is illustrated in Fig. 2. 


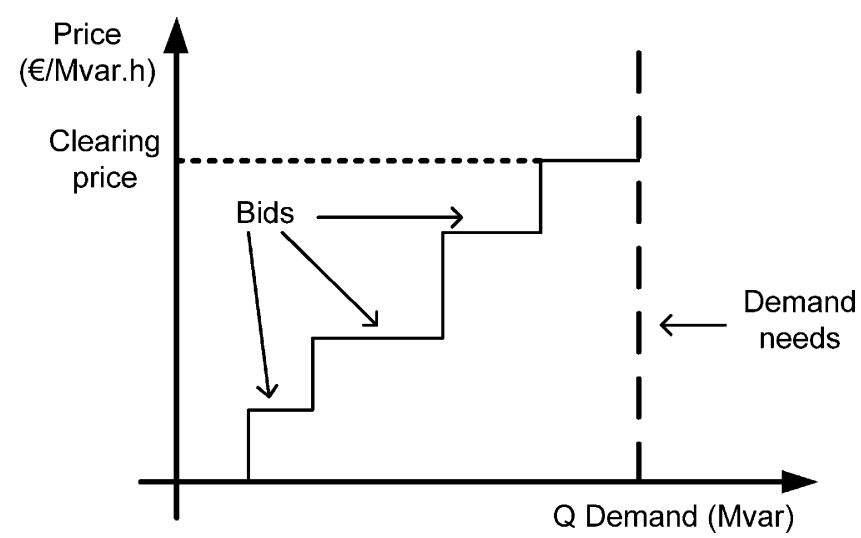

Fig. 2. Day-ahead market structure for voltage control for each hour.

\subsection{Mathematical formulation}

The proposed procedure for achieving the market settlement is based on an OPF-like routine that defines the cleared bids from market players, according to the formulation shown below.

$\min \sum_{j=1}^{M} p_{j}^{b i d}$

Subject to

$P_{i}^{G}-P_{i}^{L}=\sum_{k=1}^{N} V_{i} \cdot V_{k} \cdot\left(G_{i k} \cdot \cos \theta_{i k}+B_{i k} \cdot \sin \theta_{i k}\right)$

$Q_{i}^{G}-Q_{i}^{L}=\sum_{k=1}^{N} V_{i} \cdot V_{k} \cdot\left(G_{i k} \cdot \sin \theta_{i k}-B_{i k} \cdot \cos \theta_{i k}\right)$

$Q_{i}^{G}=\sum_{j=1}^{M} Q_{i j}^{b i d}+\sum_{j=1}^{M} Q_{i j}$

$S_{i k} \leq S_{i k}^{\max }$

$V_{i}^{\min } \leq V_{i} \leq V_{i}^{\max }$

$Q_{i}^{\min } \leq Q_{i}^{G} \leq Q_{i}^{\max }$

where $p_{j}^{b i d}$ is the price of the reactive power bid from unit $j ; P_{i}^{G}$, $P_{i}^{L}$ is the active power generation/consumption at bus $i$, respectively; $V_{i}$ is the voltage at bus $i ; G_{i k}$ is the real part of the element in the Admittance Matrix ( $Y_{b u s}$ ) corresponding to the $i$ th row and $k$ th column; $B_{i k}$ is the imaginary part of the element in the $Y_{b u s}$ corresponding to the $i$ th row and $k$ th column; $\theta_{i k}$ is the difference in voltage angle between the $i$ th and $k$ th buses; $Q_{i}^{G}, Q_{i}^{L}$ is the reactive power generation/consumption at bus $i$, respectively; $Q_{i j}^{b i d}$ is the reactive power generation corresponding to the bid of unit $j$ at bus $i$; $Q_{i j}$ is the reactive power generation of unit $j$ at bus $i$ not offered to the var market; $S_{i k}$ is the apparent power flow in branch $i k ; S_{i k}^{\max }$ is the maximum apparent power flows in branch $i k ; V_{i}$ is the voltage at bus $i ; V_{i}^{\min }, V_{i}^{\max }$ is the minimum and maximum voltage at bus $i$, respectively; $Q_{i}^{G}$ is the reactive power generation at bus $i$; $Q_{i}^{\min }$, $Q_{i}^{\text {max }}$ is the minimum and maximum reactive power generation at bus $i$, respectively.

The main goal from the DSO perspective is to minimize the purchases of var capacity, considering certain operational and security criteria. The main equality constraints considered in Eqs. (3-2)-(34) are related to the non-linear active power balance equations and reactive power balance equations. The inequality constraint shown in Eq. (3-5) is related to apparent power flow limits of branches and the constraints in Eqs. (3-6) and (3-7) concern other technical and operational limits such as bus voltage limits and reactive power generation limits.

\subsection{Market players}

Several different players may wish to access the var market. DG units directly connected to the MV level of the distribution system may wish to bid their reactive power generation capacity or, alternatively, some of the reactive power required by the DSO may be bought from the upstream HV distribution network. Microgrids may also bid to this market through the corresponding MGCC, which acts as an aggregator of microsource capacities and collects the offers from the several microgeneration units within the microgrid.

Therefore, the main var supplying sources, which can be considered as control variables in this formulation, are:

- HV network (if available);

- MV-connected DG units;

- Microgrids.

The several players that wish to participate in the AS market for voltage control must provide their bids to the DSO, which is in charge of market settlement. The players willing to enter the var market can organize their bids in blocks: each pre-determined amount of reactive power (in Mvar) at a rated price for each of the $24 \mathrm{~h}$ of the next day.

\section{Development of the approach}

A general overview of the proposal developed in this thesis is shown in Fig. 3. First of all, the var sources participating in the market (var suppliers in Fig. 3) should be identified and present their bids (var bids in Fig. 3) to the DSO, which is in charge of the var market settlement. The DSO is also responsible for establishing the var demand. Consequently, the scenarios for the day-ahead AS market are defined based on load and RES forecasts and on the generation scheduling. Prior to the AS market, all generators should have communicated their availability and active power generation levels to the DSO, regardless of them participating in the market or having feed-in tariffs. Considering all var bids presented by the market players and the var demand set by the DSO enables the market settlement by running the OPF-like algorithm presented in Section 3.1 for the 24-h of the next day.

If for any reason the generation scheduling from the previous day is not feasible, it is assumed that an intra-day corrective market mechanism be activated in order to compensate the deviations that have occurred.

The result of the market settlement (through the OPF-like routine) is a set of cleared bids for the selected market players and a market price defined as the value of the bid corresponding to the marginal unit. This market price is the uniform price that is due for all market players.

The AS market for voltage control as proposed here is assumed to be a functionality to be included in the CAMC, which is in charge of the multi-microgrid system as seen in Section 2.

\subsection{Microgrid policies}

As previously seen, a microgrid may participate in both energy and ancillary services market through the corresponding MGCC, which will serve as an aggregator of the bids from the DER (including responsive loads, microgenerators and storage devices) located in the LV network. 


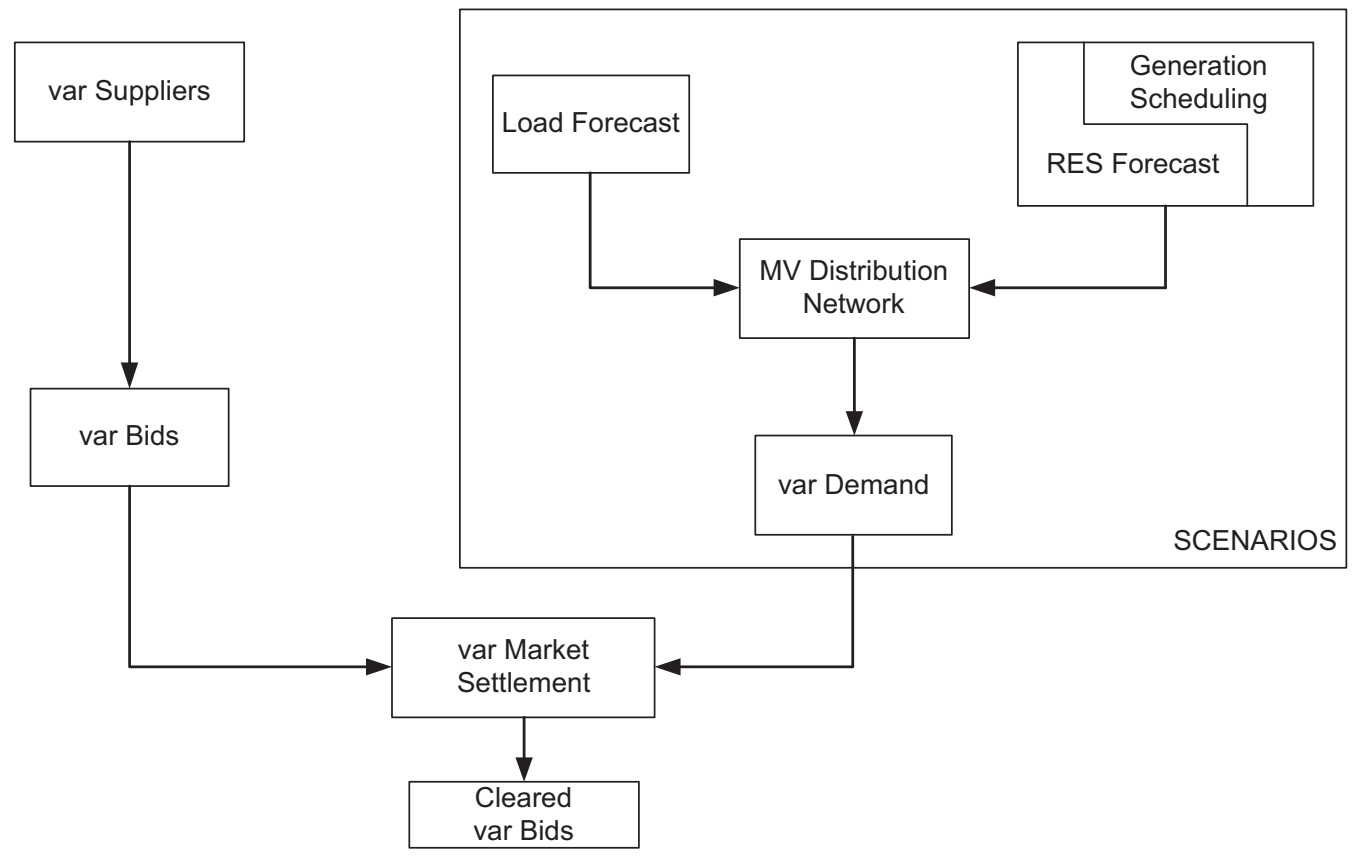

Fig. 3. Overview of the var market proposal.

In [8], Saraiva and Ribeiro present an approach to schedule microgeneration and validate the dispatch from a technical point of view using a linearized optimization problem. In this paper, the authors propose three possible approaches for economic scheduling: (1) legal enforcement, where it is legally imposed that all power from microsources must be accepted by the distribution system and remunerated according to a pre-specified tariff (feed-in tariff); (2) signal approach, where there is an initial dispatch by the wholesale market operator without microgeneration contribution (validated by the DSO) and afterwards the MGCCs proposes to replace some generation from traditional power stations adjusting the day-ahead dispatch; (3) the MGCC is considered as a market agent that collects $\mathrm{MC}$ and $\mathrm{LC}$ bids and receives information about the market clearing price and dispatched quantities.

According to the latter approach, the microgrid operates similarly to a VPP and the MGCC acts as an aggregator that collects bids and offers from the several microgenerators and loads under its control.

Market participation of microgrids exploits the hierarchical control structure inherent to the microgrid concept. In order to determine the possible contribution to the requested service by microgrids, two microgrid market policies may be envisioned [9]:

- "Good-citizen" - the microgrid serves only its own consumers, requesting zero reactive power from the grid.

- "Ideal-citizen" - the microgrid participates in the market by buying and selling active and reactive power from/to the grid.

Considering the "good-citizen" policy, the MGCC tries to meet the active power demand according to market prices and production costs. High market prices usually mean that there is peak demand at the whole grid. Due to the high prices, it is beneficial for microsources to produce energy in order to minimize the overall cost of microgrid operation. On the other hand, the microgrid tries to maintain zero reactive power demand from the grid, if possible.

The term "good-citizen" is used because the distribution grid is not burdened by the reactive power demand of the microgrid and at the time of the peak demand and high prices, the microgrid relieves possible network congestion by supplying some of its own energy needs. This means that, according to this policy, the microgrid is able to behave like a controllable load.

The "ideal-citizen" policy assumes that the microgrid serves its own needs, but it is also able to participate in the market by presenting bids through an aggregator. The MGCC tries to maximize the value of the microgrid by maximizing the gains from the power exchange with the grid. Consequently, the ideal-citizen policy fully enables the provision of ancillary services to the main distribution system.

\section{Test network}

A study-case MV test network, using real data, developed within the framework of the More MicroGrids project was used in this paper [10]. This test network is shown in Fig. 4 and contains several MV-connected DG sources namely a Diesel generator, a Doubly-Fed Induction Generator based (DFIG) wind farm, a Hydro asynchronous unit and a Combined Heat and Power (CHP) synchronous unit.

Several LV networks are connected to this MV network including five "active" networks - microgrids. The microgrids were modelled as an equivalent load (corresponding to the sum of all LV loads) and an equivalent generator (corresponding to the sum of all microgeneration units), as can be seen in Fig. 4. It is assumed that these microgrids have a combination of different types of microgenerators, both controllable (such as microturbines) and non-controllable (such as PV), in order to ensure that some reactive power can be injected into the main MV network. The data regarding the test system used can be provided upon request.

\section{Results}

The market simulator for ancillary services addressing voltage control has been developed in the MATLAB ${ }^{\odot}$ environment using the base OPF solver from MATPOWER ${ }^{\odot}[11]$ with some modifications. Several simulations have been performed using the test network presented. In this section, a scenario for the peak hour (corresponding to the highest demand for energy) is presented for illustrating the performance of the ancillary services market simulator. 


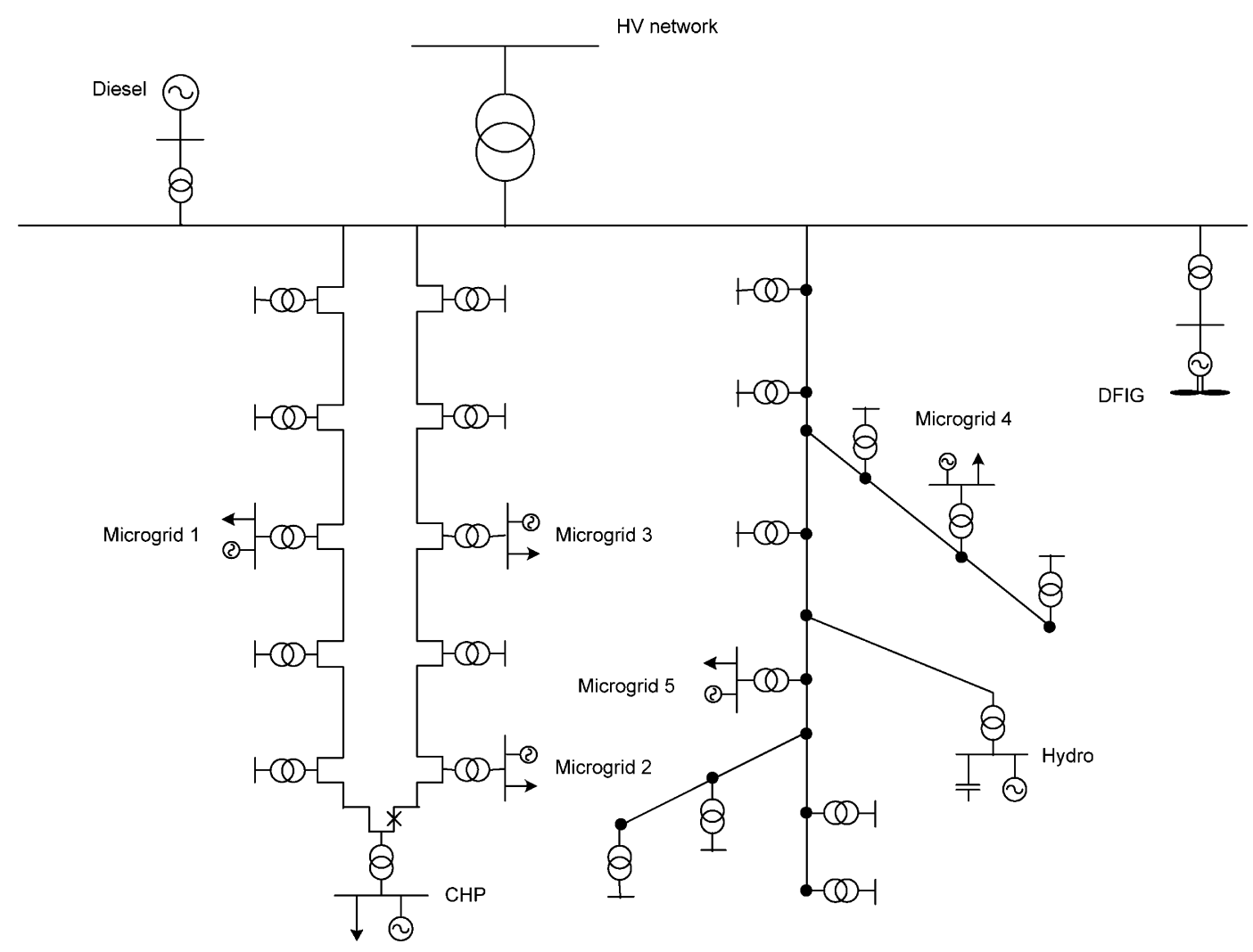

Fig. 4. MV test network.

In this case the var suppliers bidding to the market are the 4 MV-connected DG sources (the CHP unit, the DFIG unit, the Diesel unit and the Hydro unit) and the 5 microgrids, as shown in Fig. 4. Despite the fact that the prices used for the var bids from the several units are not real prices, the price paid for reactive power supply for DG units in Portugal was considered as reference, which was around $16 € /$ Mvar $h$ for the year of 2009 [12]. Hence, the prices of the bids were defined with values around this reference by introducing some variations according to the type of generator and the amount of reactive energy required.

In this case, all generators have already provided their expected active power generation levels to the DSO and the scheduling for active power is assumed to have been defined by the DSO with success for all generating units (including RES, based on the results from forecast modules) for the following operating period. The generation scheduling results are presented in Table 1 .

The reactive power bids from the several participants in the ancillary services market for voltage control considering both the "good-citizen" and "ideal-citizen" microgrid policies are presented in Tables 2 and 3, respectively.

Table 1

Generation scheduling for the peak hour.

\begin{tabular}{ll}
\hline Generation unit & $P[\mathrm{MW}]$ \\
\hline CHP & 1.839 \\
Hydro & 0.425 \\
DFIG & 1.313 \\
Diesel & 1.288 \\
HV network & 0.628 \\
Microgrid 1 & 0.250 \\
Microgrid 2 & 0.250 \\
Microgrid 3 & 0.250 \\
Microgrid 4 & 0.250 \\
Microgrid 5 & 0.250 \\
Total & 6.743 \\
\hline
\end{tabular}

Figs. 5 and 6 show the evolution of the cleared bids towards market settlement considering the "good-citizen" and the "idealcitizen" policies, respectively. It can be observed that there were different closing prices for the market settlement concerning the microgrid policy used. In this case, the "ideal-citizen" policy corresponded to a lower price (19€/Mvar h in opposition to $21 € /$ Mvar $h$ for the "good-citizen" policy) for the DSO in order to ensure the required var demand.

The selected var bids per technology are presented in Fig. 7, comparing the "good-citizen" and the "ideal-citizen" policies. As can be observed, considering the "ideal-citizen" policy, the microgrids are able to bid reactive power to the market and, consequently, there is no need to import reactive power from the upstream network.

Tables 4 and 5 show the var bids and prices after the market settlement considering the "good-citizen" and the "ideal-citizen" policies, respectively.

Table 2

Reactive power bids for the var market ("good-citizen") for the peak hour.

\begin{tabular}{llll}
\hline Generation unit & Block number & Quantity [Mvar h] & Price [€/Mvar h] \\
\hline CHP & 1 & 0.19 & 16.00 \\
& 2 & 0.27 & 17.00 \\
Hydro & 3 & 0.27 & 18.00 \\
& 1 & 0.02 & 18.00 \\
DFIG & 2 & 0.03 & 19.00 \\
& 3 & 0.03 & 20.00 \\
\multirow{3}{*}{ Diesel } & 1 & 0.06 & 17.00 \\
& 2 & 0.10 & 18.00 \\
\multirow{3}{*}{ HV network } & 3 & 0.10 & 19.00 \\
& 1 & 0.10 & 16.00 \\
& 2 & 0.20 & 17.00 \\
& 3 & 0.20 & 18.00 \\
& 2 & 2.00 & 21.00 \\
& 3 & 2.00 & 21.00 \\
\end{tabular}


Table 3

Reactive power bids for the var market ("ideal-citizen”) for the peak hour.

\begin{tabular}{llll}
\hline Generation unit & Block number & Quantity [Mvar h] & Price [€/Mvar h] \\
\hline CHP & 1 & 0.19 & 16.00 \\
& 2 & 0.27 & 17.00 \\
Hydro & 3 & 0.27 & 18.00 \\
& 1 & 0.02 & 18.00 \\
DFIG & 2 & 0.03 & 19.00 \\
& 3 & 0.03 & 20.00 \\
Diesel & 1 & 0.06 & 17.00 \\
& 2 & 0.10 & 18.00 \\
& 3 & 0.10 & 19.00 \\
HV network & 1 & 0.10 & 16.00 \\
& 2 & 0.20 & 17.00 \\
Microgrid 1 & 3 & 0.20 & 18.00 \\
Microgrid 2 & 1 & 2.00 & 21.00 \\
Microgrid 3 & 1 & 2.00 & 21.00 \\
Microgrid 4 & 1 & 2.00 & 21.00 \\
Microgrid 5 & 1 & 0.05 & 15.00 \\
\hline
\end{tabular}

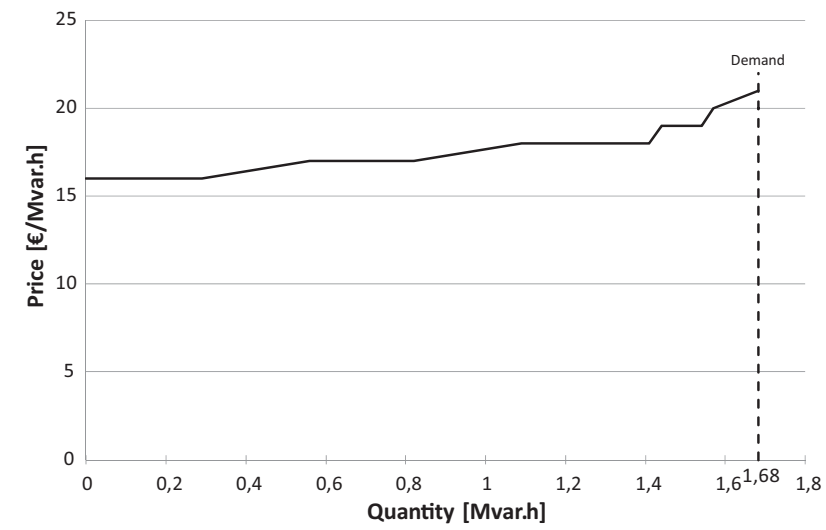

Fig. 5. Results from the market settlement ("good-citizen" policy) for the peak hour.

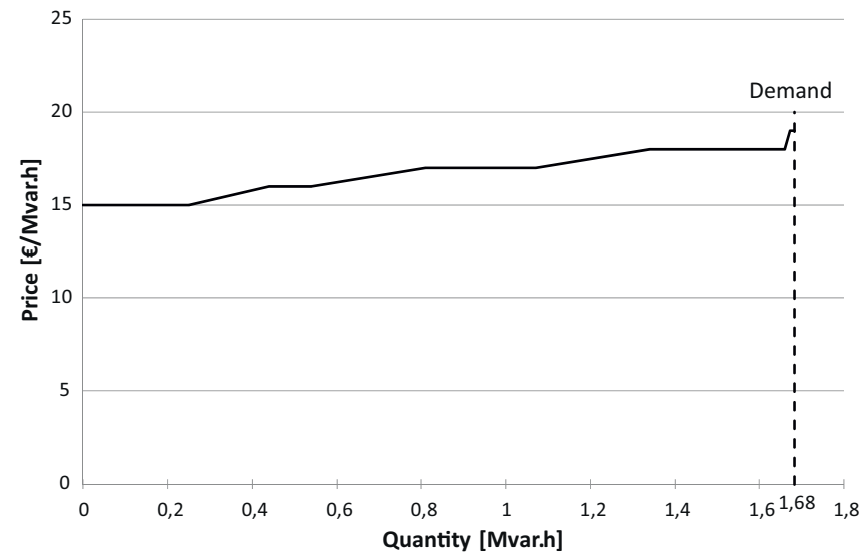

Fig. 6. Results from the market settlement ("ideal-citizen” policy) for the peak hour.

Table 4

Bids and prices ("good-citizen") for the peak hour.

\begin{tabular}{lllr}
\hline Generation unit & $Q[$ Mvar] & Price $[€ /$ Mvar $h]$ & Cost $[€]$ \\
\hline CHP & 0.730 & 21.00 & 15.330 \\
Hydro & 0.080 & 21.00 & 1.680 \\
DFIG & 0.260 & 21.00 & 5.460 \\
Diesel & 0.500 & 21.00 & 10.500 \\
HV network & 0.114 & 21.00 & 2.384 \\
Total & 1.684 & - & 35.354 \\
\hline
\end{tabular}

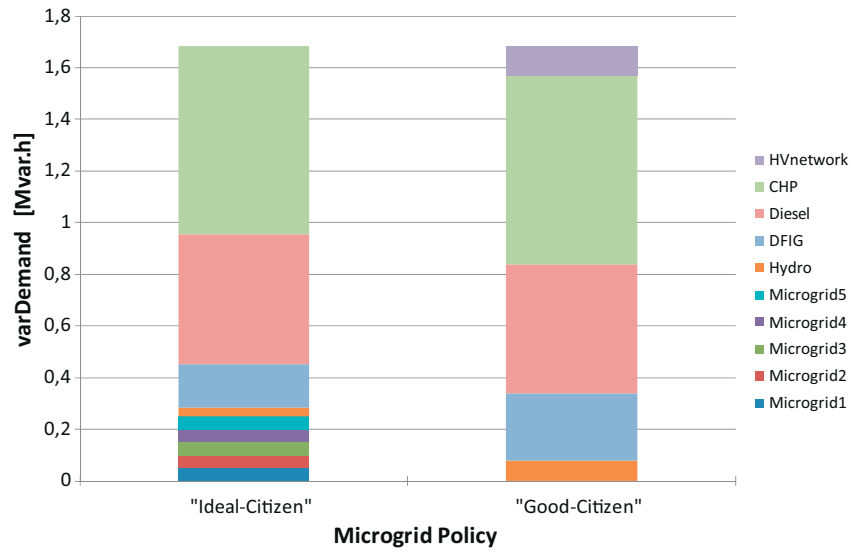

Fig. 7. Selected bids ("good-citizen" policy vs. "ideal-citizen” policy) for the peak hour.

Table 5

Bids and prices ("ideal-citizen") for the peak hour.

\begin{tabular}{lllr}
\hline Generation unit & $Q[$ Mvar] & Price $[€ /$ Mvar h] & Cost [€] \\
\hline CHP & 0.730 & 19.00 & 13.870 \\
Hydro & 0.033 & 19.00 & 0.628 \\
DFIG & 0.170 & 19.00 & 3.237 \\
Diesel & 0.500 & 19.00 & 9.500 \\
Microgrid 1 & 0.05 & 19.00 & 0.950 \\
Microgrid 2 & 0.05 & 19.00 & 0.950 \\
Microgrid 3 & 0.05 & 19.00 & 0.950 \\
Microgrid 4 & 0.05 & 19.00 & 0.950 \\
Microgrid 5 & 0.05 & 19.00 & 0.950 \\
Total & 1.683 & - & 31.984 \\
\hline
\end{tabular}

From the previous tables it can be seen that there is a small advantage in terms of costs for the DSO in terms of price of the reactive power bids submitted by the DG units and microgrids for the "ideal-citizen" policy compared to the "good-citizen" policy.

\section{Conclusions}

The participation of DG in network operation, especially by providing ancillary services such as voltage support, will be one of the key drivers for fostering the integration of DER in electrical distribution systems.

A proposal for a local ancillary services market for voltage control has been developed based on a daily market for var capacity use. An innovative contribution of this research is that the main providers of the service can be both DG units and microgrids.

Considering the architecture of multi-microgrid systems presented, a microgrid can be operated similarly to a VPP from the MV distribution system point of view, where the MGCC will act as an aggregator collecting bids from several DER connected to the LV network.

Regarding ancillary services provision for voltage control, an optimization formulation is used to select efficiently the reactive power bids based on an OPF-like routine. The main objective of this optimization problem is to minimize costs associated with the purchase of reactive power capacity by the DSO subject to technical and operational constraints. The results from the OPF provide the market settlement and define the cleared bids and corresponding market price.

Two policies for microgrid market participation can be envisioned: "good-citizen" and "ideal-citizen". From the results obtained, it was seen that the "ideal-citizen" policy for microgrids is able to increase efficiency by avoiding the need for importing 
reactive power from the upstream HV network and take full profit of the resources available locally.

The implementation of this proposal in a real environment will require operational changes regarding the coordination of protection systems as well as the development of new tools for DMS environments. Furthermore, regulatory and commercial issues must also be effectively tackled.

\section{Acknowledgments}

This work was supported in part by the European Commission within the framework of the More MicroGrids project, Contract No. 019864 - (SES6).

A.G. Madureira wants to express his gratitude to Fundação para a Ciência e a Tecnologia (FCT), Portugal, for supporting this work under the grant SFRH/BD/29459/2006.

\section{References}

[1] J. Zhong, K. Bhattacharya, Reactive power management in deregulated electricity markets - a review, in: Proceedings of the IEEE Power Engineering Society Winter Meeting, 2002.
[2] P.M. Costa, M.A. Matos, Assessing the contribution of microgrids to the reliability of distribution networks, Elect. Power Syst. Res. 79 (2) (2009) 382 389.

[3] M. Braun, Technological control capabilities of DER to provide future ancillary services, Int. J. Distrib. Energy Resour. 3 (3) (2007) 191-206.

[4] J.A.P. Lopes, et al., Integrating distributed generation into electric power systems: a review of drivers, challenges and opportunities, Elect. Power Syst. Res. 77 (9) (2007) 1189-1203.

[5] J.A.P. Lopes, C.L. Moreira, A.G. Madureira, Defining control strategies for microgrids islanded operation, IEEE Trans. Power Syst. 21 (2) (2006) 916924.

[6] A.G. Madureira, et al., Advanced control and management functionalities for multi-microgrids, Eur. Trans. Elect. Power 21 (2) (2011) 1159-1177.

[7] More MicroGrids the Project Website. http://www.microgrids.eu/index.php, 2011 (last accessed 06.06.11).

[8] J.T. Saraiva, A. Ribeiro, Development of a market approach to integrate microsources in LV distribution networks, in: IEEE Powertech, St. Petersburg, June, 2005.

[9] N. Hatziargyriou, et al., Management of microgrids in market environment, in: International Conference on Future Power Systems, Amsterdam, November, 2005.

[10] N. Gil, J.A.P. Lopes, Description of a Test Network for Simulation Platform Development, INESC Porto, More MicroGrids Internal Report, July 2006.

[11] R.D. Zimmerman, C.E. Murillo-Sánchez, R.J. Thomas, MATPOWER steady-state operations, planning and analysis tools for power systems research and education, IEEE Trans. Power Syst. 26 (1) (2011) 2-19.

[12] Decree-Law 363/2007, Ministry of Economy and Innovation, Portugal, 2007. 